Revista Duazary

ISSN: $1794-5992$

Vol. 12

No. 2

$100-111$

Julio - Diciembre de 2015

\title{
ESTRATEGIAS LÚDICAS PARA AUMENTAR EL CONOCIMIENTO DE UN GRUPO DE ADOLESCENTES ESCOLARIZADOS SOBRE LA GINGIVITIS
}

\author{
PLAYFUL STRATEGIES THAT INCREASE THE KNOWLEDGE OF \\ STUDENTS ON GINGIVITIS
}

TITULO CORTO: ESTRATEGIAS LÚDICAS PARA AUMENTAR EL CONOCIMIENTO DE UN
GRUPO DE ADOLESCENTES

Melissa Katherine Sánchez-Peña ${ }^{1}$, Kelly Johana Sánchez-Delgado ${ }^{2}$ y Alexandra Agudelo-Ramírez ${ }^{3}$

Recibido en marzo 03 de 2015

Aceptado en mayo 20 de 2015

\section{RESUMEN}

El objetivo de la investigación fue formular e implementar estrategias lúdicas para aumentar el nivel de conocimiento sobre gingivitis asociada a la placa dental y su prevención en un grupo de adolescentes de la institución educativa Alfonso Jaramillo Gutiérrez de la ciudad de Pereira. La investigación parte de la premisa de que las metodologías tradicionales de enseñanza han sido poco efectivas y se considera que las estrategias lúdicas fortalecen la participación activa de la comunidad sujeto de intervención. Se adoptó un enfoque cualitativo, postura metodológica de carácter dialógico donde las creencias, mitos, prejuicios y sentimientos son aceptados como elementos de análisis para producir conocimiento. El método de investigación fue la investigación acción y se usaron los talleres pedagógicos y grupos focales como técnicas de investigación. Se evidenció que el nivel de conocimiento inicial de los adolescentes era bajo, la mayoría de ellos desconocían la gingivitis asociada a la placa dental y con las estrategias lúdicas realizadas se aumentó el conocimiento, se obtuvo un aprendizaje significativo y la participación activa de los adolescentes.

Palabras clave: gingivitis; placa dental; adolescente; participación comunitaria; estrategias lúdicas (fuente DeSc)

\section{ABSTRACT}

The purpose of this research was to formulate and implement playful strategies to increase the level of knowledge in a group of students about gingivitis associated with bacterial plaque and its prevention, this project was developed in Pereira city at Alfonso Jaramillo Gutiérrez high school. The studio started from assuming that traditional teaching methodologies have proved to be highly ineffective and considering that playful strategies strengthen the active participation of the subject community of intervention. A qualitative approach was adopted, this methodology is

1. Odontóloga egresada de la Fundación Universitaria Autónoma de las Américas, sede Pereira, Colombia. Correo electrónico: meli2_7@hotmail.com

2. Odontóloga egresada de la Fundación Universitaria Autónoma de las Américas, sede Pereira, Colombia. Correo electrónico: kellysanchezdelgado@gmail.com

3. Magíster en Educación y Desarrollo Humano. Ingeniera industrial. Miembro del Grupo de Investigación en Salud y Comunidad -GISCo- y Docente del programa

Salud Comunitaria de la Fundación Universitaria Autónoma de las Américas, sede Pereira, Colombia. Correo electrónico: alexandra.agudelo@uam.edu.co 
characterized by its dialogic nature where beliefs, myths, prejudices and feelings are accepted as elements of analysis to produce knowledge. The research method chosen was the Action Research and teaching workshops and focus groups were used as investigation techniques. It was proved that the initial level of knowledge of these teenagers was low. Most of them were totally unfamiliar with the gingivitis associated with dental plaque and through the playful strategies they increased their knowledge, obtained meaningful learning and achieved an active participation.

Keywords: gingivitis; dental plaque; adolescent; consumer participation; playful strategies.(fuente DeCs)

\section{INTRODUCCIÓN}

L a salud pública se define como "aquellas políticas y actividades que se realizan para y con la comunidad, con el fin de promover la salud y prevenir la enfermedad y así contribuir a un desarrollo social sostenible"1, consecuentemente la Organización Mundial de la Salud (OMS) elaboró la Carta de Ottawa en 1986, donde se explica la promoción general en salud la cual "consiste en proporcionar a los pueblos los medios necesarios para mejorar su salud y ejercer un mayor control sobre la misma" y define la prevención como "la aplicación de medidas técnicas que incluye aspectos médicos y de otras disciplinas que tienen como finalidad impedir la aparición de la enfermedad (prevención primaria), curarla (prevención secundaria) y devolverle las capacidades perdidas (prevención terciaria)"2, declarando que la promoción y la prevención deben ejercerse simultáneamente ya que es una estrategia de acción en salud para todo el mundo.

A pesar de que se han invertido recursos importantes en Colombia en cuanto a salud pública, las enfermedades bucodentales siguen siendo las más prevalentes ${ }^{3}$, algunos autores atribuyen este fenómeno a que el conocimiento se transmite y no se construye con las comunidades, lo que puede desencadenar un distanciamiento entre las visiones de los profesionales de la salud y la población ${ }^{4}$. Además, las estrategias de promoción y prevención en muchos casos no son diseñadas de acuerdo con el contexto de las poblaciones ni sus necesidades. Por lo tanto, generar cambios culturales hacia la adopción de prácticas adecuadas relacionadas con la salud bucal es una meta que no se ha alcanzado.

Según el Tercer Estudio Nacional de Salud Bucal -ENSAB"a nivel periodontal, los problemas más comunes en los niños y adolescentes fueron los cálculos y la gingivitis, para lo cual requieren básicamente atenciones de primer nivel tipo refuerzos en higiene oral y detartrajes

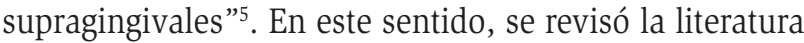
científica donde se evidencia que los adolescentes no reconocen los signos de la gingivitis, por consiguiente desconocen los diferentes métodos para su prevención ${ }^{6-8}$ dificultando así que los índices de la gingivitis asociada a placa bacteriana disminuyan.

A través de la revisión sistemática realizada en bases de datos se comprueba escasez de estudios latinoamericanos sobre salud oral con población adolescente, por otro lado, se ha reportado en investigaciones con menores de trece años de edad el impacto positivo y el aumento de conocimiento acerca de la prevención de las enfermedades bucodentales. Igualmente, se ha demostrado que se puede lograr una adecuada promoción de la salud por medio de intervenciones educativas lúdicas en una comunidad, según estudios nacionales ${ }^{9}$ internacionales desarrollados en países como $\mathrm{Cuba}^{10}$, Perú ${ }^{11}$ y México ${ }^{12}$.

Es importante resaltar que en Pereira, la Secretaría de Salud implementa acciones de prevención de la enfermedad y promoción de la salud en las instituciones educativas por medio del programa Escuelas Saludables, que tiene como objetivo promover estilos de vida saludables, dentro del cual se encuentra el programa de salud oral dirigido a estudiantes menores de trece años de edad y enfocado en prevención de la caries dental ${ }^{13}$. Sin embargo, dicho programa no incluye la prevención de la gingivitis asociada a la placa dental y excluye a la población adolescente de las acciones de promoción y prevención. Además, hay pocos estudios con adolescentes que relacionen el aumento del conocimiento acerca de enfermedades bucodentales y su prevención con el uso de estrategias lúdicas, al contrario de lo que se ha realizado con la población infantil. 
Con el fin de incluir a la población adolescente en la prevención de la gingivitis asociada a la placa dental, se parte de la siguiente premisa: para que la educación para la salud sea efectiva y genere impactos requiere el uso de metodologías participativas que promuevan la autonomía de las comunidades o poblaciones con las que se trabaja. En consecuencia, se utilizaron en esta investigación estrategias lúdicas, entendidas como aquellas que promueven la participación activa, estimulan la creatividad, generan relaciones horizontales que permiten un compartir de saberes entre los participantes y los investigadores, promueven un ambiente para disfrutar el aprendizaje, hacen que los estudiantes sean dinamizadores del proyecto y pueden ser desarrolladas con materiales sencillos. Además, dichas estrategias implican no solo la dimensión cognoscitiva sino también la emocional y corporal, y se convierten en un medio para que las personas hagan conciencia de cuáles hábitos afectan su salud bucal, es decir, son estrategias para problematizar las acciones en la cotidianidad ${ }^{14,15,16}$.

La principal técnica usada en la investigación consistió en talleres pedagógicos, que pueden usarse como estrategia lúdica, porque al definirse como una reunión donde se unen en pequeños grupos de trabajo para realizar aprendizajes prácticos según los objetivos propuestos ${ }^{17}$, brindaban la flexibilidad para introducir la práctica a través de la lúdica con unos propósitos claros de aprendizaje.

El uso de la lúdica como estrategia pedagógica busca que el aprendizaje sea significativo, es decir, que se realice una mejor orientación de la labor educativa en salud, pues se parte de los conocimientos y experiencias que tienen los participantes, por lo cual se afirma que no es un proceso que parta de $\operatorname{cero}^{18}$ y no se reduce a la memorización mecánica carente de sentido ${ }^{19}$. Es así como el uso de recursos didácticos como la lúdica y el juego permiten al estudiante obtener un aprendizaje significativo toda vez que él construye sus propios esquemas de conocimiento ${ }^{20}$. Barbato, citado por Gaete, afirma que "la actividad lúdica permite al jugador (estudiante) una organización de ideas de tal suerte que pueda extraer aquellas consideradas como fundamentales para relacionarlas con otras situaciones, haciendo que el aprendizaje sea significativo"21.

102

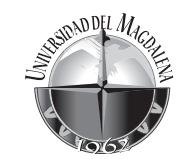

Por lo anteriormente evidenciado es importante abordar la educación para la salud en adolescentes a través de estrategias lúdicas pues, por un lado, los adolescentes tienen una percepción de riesgo de enfermedad muy baja $^{6}$, y por otro, la adolescencia es un momento indicado para aprender y adaptar nuevos modelos de vida ${ }^{22,23}$. El uso de este tipo de estrategias permite partir de la realidad de los adolescentes, de su percepción y sus propios planteamientos acerca de las cuestiones que se pretenden $\operatorname{trabajar}^{22}$, por lo que se hace necesario utilizar metodologías que los vinculen activamente, les permitan salir de la monotonía de las clases tradicionales, que los lleven a estimular la creatividad y la capacidad de generar propuestas, facilite el aprendizaje con los pares en una etapa en la que las relaciones interpersonales son fundamentales ${ }^{24}$.

Por ello, el presente estudio se realizó con el objetivo de formular e implementar estrategias lúdicas que permitieran aumentar el nivel de conocimiento sobre la gingivitis asociada a la placa dental y su prevención en un grupo de adolescentes de la institución educativa Alfonso Jaramillo Gutiérrez de la ciudad de Pereira.

\section{MATERIALES Y MÉTODOS}

\section{Tipo de estudio}

Se realizó un estudio de enfoque cualitativo y se utilizó como método la investigación acción, la cual se define como un proceso reflexivo que vincula dinámicamente la investigación, la acción y la formación que se lleva a cabo en un grupo de trabajo. Además es participativo, sigue una espiral introspectiva que contiene ciclos de planificación, acción, observación y reflexión, a la vez que implica para los investigadores registrar, recopilar, analizar los propios juicios, reacciones e impresiones entorno a las diferentes situaciones que se presenten ${ }^{25}$.

El método se diseñó en fases: I) exploración y estrategia de recolección de datos sobre el nivel de conocimiento de los estudiantes sobre gingivitis asociada a la placa dental y su prevención; II) planeación y formulación de las estrategias lúdicas en conjunto con los estudiantes; III) aplicación de dichas estrategias; y IV) evaluación de resultados sobre el nivel de conocimiento adquirido.

La investigación tuvo una duración de tres (3) meses en trabajo de campo, la evaluación fue una fase transversal, la evaluación de conocimientos adquiridos se hizo con la comparación del conversatorio inicial (primera actividad) y conversatorio final (última actividad), para los cuales se usaron las mismas preguntas orientadoras (Tabla 1).

El proyecto se elaboró en el marco del currículo del programa de salud comunitaria de los estudiantes de odontología de la Fundación Universitaria Autónoma de las Américas de la sede Pereira. 
Tabla 1. Descripción de actividades realizadas en la investigación

\begin{tabular}{|c|c|c|c|}
\hline ACTIVIDAD & METODOLOGÍA & $\begin{array}{l}\text { MATERIAL } \\
\text { UTILIZADO }\end{array}$ & $\begin{array}{l}\text { TIEMPO DE } \\
\text { DURACIÓN }\end{array}$ \\
\hline $\begin{array}{l}\text { Presentación del proyecto a } \\
\text { la institución }\end{array}$ & Exposición y contextualización & $\begin{array}{l}\text { Video beam. } \\
\text { Presentación en Power } \\
\text { Point. }\end{array}$ & 90 minutos \\
\hline $\begin{array}{l}\text { Presentación de los } \\
\text { investigadores con los } \\
\text { estudiantes }\end{array}$ & $\begin{array}{l}\text { Actividad rompe hielo en donde los } \\
\text { investigadores se presentaron ante los } \\
\text { estudiantes y explicaron la investigación, } \\
\text { se entregaron los consentimientos. }\end{array}$ & $\begin{array}{l}\text { Consentimientos } \\
\text { informados para padres } \\
\text { y estudiantes. }\end{array}$ & 60 minutos \\
\hline Conversatorio inicial & $\begin{array}{l}\text { Grupos Focales: } 4 \text { grupos conformados } \\
\text { por } 10 \text { estudiantes y un Investigador. Se } \\
\text { realizó un conversatorio con preguntas } \\
\text { semi-estructuradas. }\end{array}$ & $\begin{array}{l}\text { Grabadoras de audio. } \\
\text { Formato de diarios de } \\
\text { campo. } \\
\text { Formato de preguntas } \\
\text { semi-estructuradas. } \\
\text { Obsequios. } \\
\end{array}$ & 90 minutos \\
\hline $\begin{array}{l}\text { Lúdica: anatomía dental y } \\
\text { periodontal, placa bacteriana }\end{array}$ & $\begin{array}{l}2 \text { grupos de } 20 \text { estudiantes cada uno a } \\
\text { cargo de } 2 \text { investigadores. } \\
\text { Los estudiantes identificaron las partes } \\
\text { del diente. } \\
\text { Se integraron los conceptos en un } \\
\text { crucigrama con adivinanzas. } \\
\text { Se dan obsequios. }\end{array}$ & $\begin{array}{l}\text { Carteleras con dibujos. } \\
\text { Imágenes de placa } \\
\text { bacteriana. } \\
\text { Dientes de ivorina. } \\
\text { Fotocopias de } \\
\text { crucigrama y } \\
\text { adivinanzas. } \\
\text { Obsequios. } \\
\end{array}$ & 120 minutos \\
\hline $\begin{array}{l}\text { Lúdica: gingivitis asociada a } \\
\text { placa bacteriana }\end{array}$ & $\begin{array}{l}2 \text { grupos de } 20 \text { estudiantes cada uno a } \\
\text { cargo de } 2 \text { investigadores. } \\
\text { Explicación sobre gingivitis asociada a } \\
\text { placa bacteriana a través de un video. } \\
\text { Se entregó una cartilla explicando la } \\
\text { gingivitis. } \\
\text { Juego del Manotazo con cartas y } \\
\text { preguntas. }\end{array}$ & $\begin{array}{l}\text { Cartillas. } \\
\text { Juego de cartas. } \\
\text { Video de la gingivitis. } \\
\text { Computador. }\end{array}$ & 90 minutos \\
\hline $\begin{array}{l}\text { Lúdica: evaluar los } \\
\text { conocimientos ya } \\
\text { aprendidos y la evolución de } \\
\text { la gingivitis }\end{array}$ & $\begin{array}{l}2 \text { grupos de } 20 \text { estudiantes cada uno a } \\
\text { cargo de } 2 \text { investigadores. } \\
\text { Evolución de la gingivitis a través de } \\
\text { diapositivas animadas con participación } \\
\text { de los estudiantes e investigadores. } \\
\text { Se jugó quien quiere ser millonario con } \\
\text { preguntas de los temas de las actividades } \\
\text { lúdicas anteriores. }\end{array}$ & $\begin{array}{l}\text { Presentación en power } \\
\text { point. } \\
\text { Video beam. } \\
\text { Computador. } \\
\text { Juego quien quiere ser } \\
\text { millonario. }\end{array}$ & 90 minutos \\
\hline
\end{tabular}




\begin{tabular}{|l|l|l|l|}
\hline \multicolumn{1}{|c|}{ ACTIVIDAD } & \multicolumn{1}{|c|}{ METODOLOGÍA } & \multicolumn{1}{|c|}{$\begin{array}{c}\text { MATERIAL } \\
\text { UTILIZADO }\end{array}$} & $\begin{array}{l}\text { TIEMPO DE } \\
\text { DURACIÓN }\end{array}$ \\
\hline $\begin{array}{l}\text { Lúdica: estaciones de } \\
\text { higiene oral y prevención de } \\
\text { gingivitis asociada a placa } \\
\text { bacteriana }\end{array}$ & $\begin{array}{l}\text { 4 grupos de 10 estudiantes y 4 estaciones } \\
\text { en donde se explicó: } \\
\text { Higiene oral y el mal aliento. } \\
\text { 1. Técnica de cepillado y entrega de kit } \\
\text { de higiene oral. } \\
\text { 2. Uso enjuague bucal y seda dental. } \\
\text { 3. Técnica de cepillado en dos } \\
\text { macromodelos a los cuales se les simulo } \\
\text { la placa bacteriana. }\end{array}$ & $\begin{array}{l}\text { Macromodelos con } \\
\text { Rlastilina. } \\
\text { Decoración de cada } \\
\text { estación. }\end{array}$ & 60 minutos \\
\hline $\begin{array}{l}\text { Lúdica: entrega de kits de } \\
\text { higiene oral ,aplicación de } \\
\text { revelador de placa, practica } \\
\text { de la técnica de cepillado y } \\
\text { seda dental }\end{array}$ & $\begin{array}{l}\text { Dos actividades simultáneas: } \\
\text { Sopa de letras con enseñanzas sobre } \\
\text { actividades lúdicas anteriores. } \\
\text { Tinción de placa bacteriana. } \\
\text { Cepillado con técnica enseñada y usan } \\
\text { la seda dental. }\end{array}$ & $\begin{array}{l}\text { Sopas de letras. } \\
\text { Pastillas reveladoras. }\end{array}$ & 60 minutos \\
\hline Conversatorio final & $\begin{array}{l}\text { Grupos Focales: 4 grupos conformados } \\
\text { por 10 estudiantes y un investigador. } \\
\text { Se compartió un refrigerio como } \\
\text { agradecimiento por ser partícipes del } \\
\text { proyecto, se escuchan comentarios } \\
\text { y agradecimiento de parte de los } \\
\text { estudiantes. }\end{array}$ & $\begin{array}{l}\text { Formato de preguntas } \\
\text { semi-estructuradas. }\end{array}$ & 60 minutos \\
\hline
\end{tabular}

\section{Unidad de trabajo}

La población participante estuvo conformada por cuarenta estudiantes con edades entre 14 y 15 años, matriculados en el grado noveno $\mathrm{C}$ de la institución educativa Alfonso Jaramillo Gutiérrez de la ciudad de Pereira en el año 2014. La muestra fue no probabilística y a conveniencia.

La institución educativa hace parte de las comunidades de trabajo del programa de Salud Comunitaria de la Fundación Universitaria Autónoma de las Américas, el proyecto fue presentado a las directivas de la institución y a los y las estudiantes, obteniendo la aprobación para su desarrollo. La participación de los adolescentes fue voluntaria, previa firma de asentimiento informado y consentimiento informado por parte de padres y madres de familia.

\section{Recolección de la información}

La información se obtuvo utilizando las técnicas de talleres pedagógicos y grupos focales, con preguntas semi- estructuradas acerca del conocimiento de los estudiantes sobre gingivitis asociada a la placa dental y su prevención. Se utilizaron anotaciones en diarios de campo, grabaciones con sus correspondientes transcripciones y elementos producidos por los participantes.

\section{Análisis de la información}

La unidad de análisis se definió como los conocimientos de los estudiantes acerca de la gingivitis asociada a la placa dental y su prevención. El método para el análisis de la información siguió los principios de la teoría fundamentada ${ }^{25}$, el cual inició con la constitución de los datos que permitió agruparlos, compararlos y analizarlos mediante una lectura sistemática y cuidadosa de la información. Posteriormente se procedió a realizar la codificación, la cual inició con un primer análisis del material que permitió generar, por comparación constante, diversas categorías iniciales de significado y sus correspondientes subcategorías, proceso denominado codificación abierta. El último paso consistió en realizar una codificación axial, donde se seleccionó la categoría 
central “conocimiento de Gingivitis”, relacionándola con las demás categorías realizando un paradigma codificado. Finalmente se compararon las anotaciones del conversatorio inicial con las del conversatorio final bajo las categorías que surgieron en la codificación axial.

\section{Aspectos éticos}

La investigación se realizó con menores de edad, por lo tanto, se utilizó un formato de asentimiento informado para estudiantes y uno de consentimiento informado para madres y padres de familia. El proyecto recibió el aval del Comité de Ética y Bioética de la Fundación Universitaria Autónoma de las Américas. De acuerdo a la Resolución 0008430 de 1993 la investigación se clasifica como de riesgo mínimo por cuanto no se manipula la conducta de los sujetos.

\section{RESULTADOS}

Los resultados se presentan de acuerdo a las fases de la investigación enunciadas en el apartado anterior, evidenciando el antes, durante y después de las estrategias lúdicas. Cabe anotar que en los talleres realizados solo faltaron dos estudiantes en dos encuentros, además se presentó una participación activa, es decir, se escucharon las voces de todos gracias a la estrategia de trabajar en grupos pequeños; cada encuentro finalizó con actividades evaluativas, lo que facilitó a cada uno hacer un repaso de lo aprendido.

La población participante estuvo conformada por 40 estudiantes de noveno grado, 16 mujeres y 24 hombres entre 14 y 15 años, estrato socioeconómico 2, 3 y 4, residentes en la comuna Cuba, en su mayoría afiliados al régimen subsidiado de salud. Es importante aclarar que en la institución educativa no se estaba desarrollando algún proyecto sobre salud en el momento de la realización de la investigación.

\section{Nivel de conocimiento inicial}

A partir del análisis de las respuestas de los estudiantes en los grupos focales iniciales se determinó que el conocimiento inicial de ellos sobre la gingivitis asociada a la placa dental era bajo.

Anatomía dental: los estudiantes manifestaron no saber las partes del diente, algunos mencionaron diferentes partes anatómicas de la cavidad oral; además, no diferenciaron anatómicamente entre diente y encía, aunque algunos de los estudiantes distinguieron dichas estructuras por su función. Tal como lo expresaron los participantes (se omiten los nombres de los estudiantes y se reemplazan por "E" y el número asignado en la codificación a cada uno de ellos):

"Las partes de los dientes son los molares, colmillos, cordales y encía” E2

"La encía recubre el diente y el diente tritura la comida" E22

"Esta es la encía" (señalando su paladar) E6

Placa dental: gran parte de los estudiantes no tenían conocimiento sobre la placa dental, algunos la asociaron con bacterias, materia y manchas dentales y otros determinaron que era una enfermedad bucodental.

Conocimiento de la gingivitis asociada a la placa dental (signos clínicos): los conceptos manifestados por los estudiantes fueron errados en su mayoría, ya que relacionaron la gingivitis con enfermedades de diferentes partes del cuerpo, una mínima parte de la población sujeto identificó esta patología como una enfermedad de las encías.

"La gingivitis es una enfermedad de los ojos como conjuntivitis" E1

"La gingivitis es una enfermedad del paladar" E11

"La gingivitis la he escuchado, pero no sé qué significa” E29

Los estudiantes refirieron que les han sangrado las encías espontáneamente, al cepillado o al masticar algunos alimentos, lo cual aumenta la probabilidad de que hayan padecido gingivitis asociada a la placa dental, ya que el sangrado de las encías es un signo patognomónico de esta enfermedad, pero ellos asociaron el sangrado como respuesta a trauma por el cepillado o los alimentos.

Hábitos de higiene oral: expresaron que la seda dental se utiliza solo para retirar los restos de comida interproximal, es importante aclarar que algunos no conocían este implemento de higiene oral. También asociaron el enjuague bucal exclusivamente con la eliminación del mal aliento, aunque para evitarlo los estudiantes emplean dulces refrescantes, como chicles y mentas. Asimismo, desconocían la causa de este y tenían información errónea. Las siguientes respuestas confirman lo anterior:

"Solo utilizo la seda para quitarme la carne entre los dientes" E33 
"Un profesor nos dijo que el mal aliento daba por hablar mucho” E18

"Cuando yo tengo mal aliento me echo enjuague bucal y se me quita” E5

A partir de lo manifestado por los estudiantes se perciben errores conceptuales e información distorsionada o muy reducida en lo referente al uso de los elementos básicos de higiene oral y al concepto de prevención de la enfermedad bucal. Igualmente, queda claro que la enfermedad gingival es casi desconocida para los adolescentes, pues no tuvieron elementos para hacer una descripción más amplia y se limitaron a reproducir información que circula en el medio, pero sin la comprensión que se requiere para lograr un aprendizaje que pueda expresarse en prácticas saludables adecuadas.

Por lo tanto, en la formulación e implementación de las estrategias lúdicas se hizo énfasis en la enseñanza de anatomía dental y periodontal, sus diferencias, localización y función, en lo relacionado con la etiopatogenia de la gingivitis asociada a placa dental, sus signos clínicos y su evolución, y se reforzaron los hábitos de higiene oral para así prevenir dicha patología en los adolescentes.

Estrategias lúdicas formuladas y aplicadas

Se realizó la formulación de cinco estrategias con base en lo expresado por los estudiantes, ellos relacionaron las estrategias lúdicas principalmente con aprendizaje, diversión, integración y felicidad, además propusieron aprender por medio de imágenes, casos reales, videos, modelos didácticos, cartillas, juegos de mesa y adivinanzas y sugirieron que se hiciera un juego para evaluar los conocimientos adquiridos.

Las estrategias formuladas e implementadas fueron enfocadas principalmente hacia la lúdica, donde el juego y la diversión son las herramientas para afianzar los conceptos sobre la salud bucodental y prevención de la gingivitis asociada a placa dental.

Partiendo de lo anterior, en la primera actividad lúdica por medio de un modelo del diente y el periodonto se explicó la anatomía y sus diferencias, con imágenes se ilustraron la placa dental y su formación, se reconoció la anatomía en dientes de ivorina y con un crucigrama con adivinanzas se evaluaron los conocimientos adquiridos. La segunda actividad se centró en la etiopatogenia, evolución y signos clínicos de la gingivitis asociada a placa dental por medio de un video, cartillas y juegos. En la tercera se evaluaron los conocimientos hasta el momento adquiridos con el juego “¿Quién quiere ser millonario odontológico?”. En la cuarta actividad lúdica se hizo énfasis en los hábitos de higiene oral utilizando estaciones, se realizó la entrega de kits odontológicos y en la quinta estrategia se hizo revelado de placa para culminar con la puesta en práctica de las técnicas enseñadas.

\section{Nivel de conocimiento adquirido}

Es importante resaltar que en los grupos focales finales, realizados como última actividad en los tres meses de trabajo de campo, todos los estudiantes fueron más participativos que en los iniciales, en sus respuestas se pudo evidenciar mayor conocimiento sobre los temas abordados.

Anatomía Dental: los estudiantes aprendieron las partes anatómicas aunque tuvieron dificultades para identificar si las partes pertenecían a la anotomía periodontal o dental.

"Las partes del diente son: esmalte, raíz, corona, cemento, pulpa y dentina." E2

"El diente sirve para masticar y la encía recubre la raíz del diente y lo ayuda a sostener junto con el hueso" E36

Placa dental: todos tienen una respuesta acertada al expresar en diferentes palabras que la placa dental es una acumulación de bacterias, restos alimenticios y saliva, estas definiciones expresadas por los estudiantes coinciden totalmente con las explicaciones que se dieron sobre placa dental durante las diferentes actividades lúdicas.

Conocimiento de la gingivitis asociada a la placa dental (signos clínicos): los conocimientos de los estudiantes aumentaron notoriamente, ya que no solo expresaron la definición de la patología sino también su causa, sus signos clínicos, evolución y las posibles consecuencias que se desarrollan a partir de que se presente dicha enfermedad:

"La gingivitis es la inflamación y sangrado de las encías porque tenemos muchas bacterias" E1

"La gingivitis es la inflamación de las encías, el enrojecimiento y el sangrado" E11

"La gingivitis es la inflamación de las encías que si no se detiene pasaba a periodontitis y a pérdida dental” E29 
Hábitos de higiene oral: los estudiantes indicaron que la frecuencia de cepillado correcta es entre tres y cinco veces al día, además relacionaron la seda dental como elemento primordial para retirar placa dental y restos de comida interproximal, algunos conocieron la seda dental, su uso e importancia. En cuanto al uso del enjuague bucal consideraron que es útil para eliminar las bacterias restantes después del cepillado y del uso de la seda dental. De igual modo no solo atribuyeron la eliminación del mal aliento al enjuague bucal sino al conjunto de técnicas e implementos de higiene oral. Es significativo destacar que los estudiantes comprendieron que al utilizar las técnicas de higiene oral se elimina la placa dental, la cual es la principal etiología de las enfermedades bucodentales.

"La seda dental sirve para sacar los restos alimenticios que no puede sacar el cepillo que quedan entre el diente y la encía" E40

"Por mal cepillado, no utilizar la seda y como las bacterias se acumulan, sueltan los ácidos que provocan el olor desagradable" E34

"Hacer que no nos dé gingivitis es muy fácil solo tenemos que cepillarnos frecuentemente, utilizar la seda y enjuagarnos con enjuague bucal, pero lo más importante para mí es el uso de la seda dental” E27

Estrategias lúdicas: los estudiantes relacionaron las estrategias lúdicas con aprendizaje y diversión evidenciando que con las actividades realizadas aumentaron su conocimiento sobre gingivitis asociada a placa dental y su prevención; entre sus opiniones se encontraron diferencias en el momento de escoger cuál fue la estrategia lúdica de su mayor agrado.

"Aprendimos mucho sobre los dientes, la gingivitis, a cepillarnos muy bien para que no nos de eso" E25

"La que más me gusto fue ¿Quién quiere ser millonario?, crucigrama y el cepillado después de esa pastilla roja" E17

"Todas me parecieron muy buenas y como muy originales y con las cuales nos podemos ayudar de cómo cepillarnos y no tener más adelante la gingivitis o una pérdida dental” E37

"Todo lo que aprendimos es súper nuevo, y no nos lo enseñan en el colegio ni en ninguna otra parte” E32

Por comparación constante de las respuestas iniciales y finales se evidencia que los adolescentes cambiaron sus concepciones sobre la gingivitis asociada a la placa dental y su prevención teniendo en cuenta los fundamentos teóricos brindados, aumentando notoriamente los conocimientos acerca de los temas explicados por medio de las estrategias lúdicas, lo cual demuestra la eficacia de estas.

\section{DISCUSIÓN}

La información y la educación que se brindó por medio de las estrategias lúdicas está en consonancia con las necesidades de la población y no solo desde la mirada científica impositiva, ya que no se trata de resolver los problemas de salud mediante acciones asistencialistas, sino de desarrollar un acompañamiento sin perder el verdadero sentido de la promoción de la salud. Este enfoque busca promover la autonomía de las personas en sus diferentes contextos e incidir en algunos de los determinantes que afectan la salud, siendo posible a través de la participación de la comunidad en la construcción del conocimiento.

Para hacer viable este enfoque, la educación para la salud debe incorporar nuevas e innovadoras estrategias que fortalezcan la promoción de la salud. Los nuevos propósitos de promoción de la salud y prevención de la enfermedad se concentran cada vez más en el aprendizaje y en el proceso de fortalecimiento de la autonomía, incluyen brindar acceso a la información en salud pero estimulando la participación de los individuos y comunidades, pues se ha demostrado que los procesos eficaces de enseñanza parten de los intereses de la gente, se basan en sus expectativas, y ayudan a la adquisición de conocimientos y desarrollo de habilidades para fortalecer dicha participación ${ }^{22,26}$.

En concordancia con lo anterior, algunos autores hablan de una segunda etapa de la educación para la salud, que surge de las limitaciones de enfoques anteriores cuya contrapropuesta tiene una visión más amplia, que da cabida a la participación, la crítica y la emancipación en lo que se refiere al autocuidado y preservación de la salud, además, esta segunda etapa sitúa a los educadores o promotores de la salud en otra perspectiva pedagógica, como facilitadores que promuevan diálogo abierto y respetuoso con las comunidades ${ }^{24}$. Este nuevo enfoque de educación para la salud despertó un interés en el uso de técnicas participativas, que si bien aún no son frecuentes en Colombia en el campo de la salud bucal, han sido utilizadas en otros ámbitos de la promoción y la prevención ${ }^{27}$, incluyendo el abordaje de la educación lúdica ${ }^{14}$. Estas estrategias facilitan que: 
...un grupo reflexione, dialogue, comparta y analice, de una forma amena y motivadora. Esta metodología rechaza la comunicación vertical autoritaria y propone vías democráticas, que no inhiban el potencial crítico y creador de los participantes; sino que por el contrario, los estimule a ser actores del programa, a la vez que van creciendo en su capacidad de pensar y expresarse por sí mismosi6.

La presente investigación basa sus fundamentos teóricos en la educación para la salud, entendiendo que el educar es "extraer, sacar a la luz desde dentro hacia fuera además de criar, nutrir o alimentar" 28 como etimológicamente se conoce el vocablo educare. Allí, un doble sentido está implícito: conducción desde fuera dirigida por los investigadores, en este caso, pero también auto conducción por parte de los adolescentes, entendiendo que ellos no están vacíos de todo conocimiento sino que se construye nuevo conocimiento a partir de sus saberes previos. Ello implica comprender que el discente necesita ser guiado pero su decisión interna de aprender es decisiva ${ }^{28}$.

La educación para la salud debe lograr este doble sentido antes mencionado, ya que su objetivo es proporcionar a las personas un mayor control sobre sus estilos de vida y construir conocimientos que les permitan generar autocuidado, preservar salubridad y buscar atención en forma oportuna y adecuada evitando la aparición de múltiples patologías. Lo que deja entrever que la educación para la salud es el pilar fundamental de promoción de la salud y prevención de la enfermedad.

De acuerdo con lo anterior, en Colombia se ha intentado disminuir los altos índices de enfermedades bucodentales con estrategias gubernamentales de educación en salud oral masivas ${ }^{29}$, que a pesar de los esfuerzos no han obtenido los resultados esperados. Estos procesos educativos han estado centrados en la prescripción de normas y en la transmisión de información con un carácter que dificulta la expresión de los sentimientos, pre saberes, vivencias y experiencias relacionadas con la salud en general y la salud bucal en particular, ya que consideran las comunidades como recipientes vacíos donde pueden introducir saberes impartidos de manera unilateral y que impide que se presente un aprendizaje significativo por parte de estas para adoptar estilos de vida saludables que logren disminuir la alta prevalencia de las enfermedades orales. Así lo corroboraron Agudelo y Martínez, afirmando que:
Durante muchos años la planificación de programas de salud bucal y su posterior ejecución no han tenido los mejores resultados. Esto puede ser explicado dentro de un universo de posibilidades, porque no han sido gestadas desde el seno de la comunidad misma. Las herramientas y las pedagogías participativas en salud se orientan hacia el desarrollo de capacidades y criterios, favorecen la autoestima y la autodeterminación, potencian la comunicación y la construcción colectiva y validan el aprendizaje adquirido. En otras palabras, se integra un proceso democrático para la construcción de políticas y estrategias en salud bucal 30 .

También existe evidencia científica que corrobora la afirmación de que el uso de pedagogías tradicionales en educación para la salud son limitadas en sus resultados ${ }^{24}$, por cuanto se centran en la transmisión de información ${ }^{22}$, se ciñen a metodologías estandarizadas como libros de texto ${ }^{23}$ y campañas masivas ${ }^{31}$ que no movilizan actitudes ni cambios conductuales. La continuidad del uso de estas estrategias tiene que ver con que son las estrategias educativas dominantes en el sistema de educación, por lo cual la educación para la salud no está exenta ${ }^{32}$. Este tipo de educación sitúa al estudiante como consumidor de información, según el modelo de educación bancaria (acuñado por Paulo Freire); además no considera el contexto histórico social de los sujetos ni las comunidades, por lo cual se afirma que "es evidente que las estrategias educativas utilizadas no han sido las idóneas por diferentes razones, entre las que se pueden considerar no tomar en cuenta los diversos elementos que constituyen la forma de vivir, el concepto cultural y social que el sujeto tenga de la enfermedad" ${ }^{32}$.

Igualmente, se encuentra literatura que demuestra que la educación participativa tiene un impacto superior comparada con la educación tradicional ${ }^{32}$, incluyendo en un lugar protagónico a las actividades o estrategias lúdicas como estrategias pedagógicas en diferentes grupos de edades y para el tratamiento de temas de promoción de la salud ${ }^{31,33}$ y prevención de diversas enfermedades ${ }^{14}$. Otras investigaciones presentan este enfoque de educación para la salud cuando menos como una alternativa a la educación tradicional ${ }^{11}$.

En contravía con el enfoque tradicional la metodología aplicada en esta investigación permitió que el aprendizaje de los adolescentes fuera significativo, entendido según el teórico norteamericano Ausubel ${ }^{34}$ como la estructura 
de los conocimientos previos que condiciona los nuevos conocimientos y experiencias, los cuales, a su vez, modifican y reestructuran aquellos.

Es importante resaltar que inicialmente los adolescentes presentaban errores conceptuales e información distorsionada o muy reducida en lo referente a la gingivitis asociada a la placa dental, al uso de los elementos básicos de higiene bucal y al concepto de prevención de esta enfermedad, esto ilustra una problemática importante en términos de prácticas inadecuadas que afectan la salud bucal de los adolescentes, la cual no podía pasar inadvertida, por ser precisamente la institución educativa uno de los escenarios de socialización más importantes en el que se deben construir las bases de un aprendizaje significativo y permanente.

Las respuestas iniciales de los adolescentes se reconocen como conocimiento social, construido a partir de elementos aportados por las tradiciones culturales, los medios masivos de comunicación y las actividades educativas desarrolladas en la academia sin el debido espacio para la reflexión y el análisis crítico que permita la comprensión y la consecuente transformación de conceptos erróneos que no se ajustan al conocimiento científicamente elaborado.

Las estrategias lúdicas generan el espacio para dicha comprensión, ya que según Palazzo ${ }^{35}$ los adolescentes son individuos abiertos a todo pensamiento y están dispuestos a aprender, siempre y cuando sea de su interés; ésta afirmación soporta el éxito de las estrategias ya que fueron los adolescentes quienes exteriorizaron la manera de obtener los nuevos conocimientos sobre gingivitis asociada a placa dental y su prevención.

Las estrategias permitieron la reflexión participativa de los adolescentes y la acción transformadora de los conocimientos, lo que se sustenta desde la teoría de neuroaprendizaje y lúdica de Jiméne ${ }^{15}$ que parte de la premisa de que los humanos son seres lúdicos por naturaleza. Por lo tanto, el uso de la lúdica como herramienta en la enseñanza obtendrá una mejor respuesta que mejorará la percepción y comprensión del discente, teniendo en cuenta que a mayores posibilidades de expresión y satisfacción lúdica, corresponden mejores posibilidades del aumento de conocimiento y, por ende, de salud y bienestar recordando que la educación es un determinante de la salud.
La educación en salud oral es un componente fundamental para la disminución de patologías bucodentales como la gingivitis asociada a la placa dental; por ende, requiere toda la atención y priorización del Estado y de estrategias intersectoriales. Una educación de calidad y con pertinencia se reflejará en una generación que construya un desarrollo humano saludable dejando en el pasado la educación para la salud basada en un modelo educativo conductista y transmisionista ${ }^{36}$, con una marcada orientación hacia la prescripción de estilos de vida saludables, sin tener en cuenta su relación con aspectos culturales, económicos, políticos y otros que constituyen el proceso de determinación social de la salud.

Finalmente, las estrategias lúdicas realizadas aumentaron el conocimiento y permitieron la participación activa de los adolescentes. Se comprobó por medio de sus respuestas que dichas estrategias están directamente relacionadas con los aprendizajes adquiridos, siendo efectivas, ya que estuvieron basadas en las necesidades de la población y en su contexto, tomando la población como sujetos y no como objetos, teniendo en cuenta sus saberes previos generando intersubjetividad entre los saberes de la comunidad y el conocimiento científico de los investigadores, logrando así participación-acción de ambas partes, siendo el investigador el intérpretemediador de las diversas propuestas en la construcción de la salud. Por lo tanto, las estrategias de promoción de la salud y prevención de la enfermedad deben fundamentarse en la educación en salud como determinante primordial, generando propuestas específicas y no masivas, es allí donde se realiza una crítica constructiva a los proyectos gubernamentales de promoción y prevención que permitan superar la visión tecnicista de la salud pública tradicional y fundamentar una propuesta de salud colectiva contextualizada ${ }^{37}$.

\section{REFERENCIAS BIBLIOGRÁFICAS}

1. Montenegro G. Un nuevo enfoque de la salud oral: una mirada desde la salud pública Universitas Odontológica. Enero-junio, 2011; 30, (64): 101-108.

2. Organización Mundial de la Salud. Primera Conferencia Internacional sobre la Promoción de la Salud, noviembre de 1986 [Internet]. [Consultado: 2014, 11, 18] Disponible en: http://www.fmed.uba.ar/depto/toxico1/carta.pdf

3. Ministerio de Salud y Protección Social. Lineamientos para el desarrollo progresivo de acciones para el mejoramiento de la salud bucal [Internet]. [Consultado: 2014, 09, 15]. Disponible en: http://www.col.ops-oms.org/publicaciones/ lineamientos.pdf 
4. Ochoa E, Franco A, Ramírez, B. Significados del autocuidado bucal para los escolares de instituciones educativas oficiales de Medellín. Revista Nacional de Odontología. Julio-diciembre, 2011; 7 (13): 40-48.

5. Asociación Colombiana de Facultades de Odontología. Resultados del Tercer Estudio Nacional de Salud Bucal [Internet]. [Consultado: 2014, 07, 15]. Disponible en http://acfo.edu. co/investigacion/index.php/publicaciones-enlinea? id = 28:resultados-del-iii-estudio-nacionalde-salud-bucal\&catid = 20:en-linea\&

6. Macías E, García M. Intervención educativa sobre gingivitis en adolescentes. Revista Correo Científico Médico. 2012; 16 (1).

7. Mayán G, de Beche E, Sosa I, Parejo D, Morales L. Gingivitis crónica y la higiene bucal en adolescentes de la secundaria básica "Raúl González Diego”. Rev Haban Cien Méd. Sep.-dic. 2012; 11 (4): 484-495.

8. Tascón J, Cabrera G. Creencias sobre caries e higiene oral en adolescentes del Valle del Cauca, Colombia. Colomb. Med. 2005; 36 (3) 140-145.

9. González S, Álvarez LG, Bustamante AA, Atuesta C, Betancur C, Maya D et al. Promoción y prevención en salud bucal en docentes y escolares de una escuela de Medellín. Revista Colombiana de Investigación en Odontología. 2009; 1 (1) suppl: 46-57.

10. Álvarez CJ, Navas R, Rojas de Morales T. Componente educativo-recreativo-asociativo en estrategias promotoras de salud bucal en preescolares. Rev. Cubana Estomatol. Abr.jun. 2006; 43 (2).

11. Rivera WF. Estudio comparativo de los métodos tradicionales y lúdicos vivenciales en la enseñanza aprendizaje de prevención en salud bucal en niños de 11 a 13 años en el colegio nacional "Romeo Luna Victoria” del distrito de san Borja, providencia de Lima, Perú. Odontol Pediatr. Ene-jun 2009; 8 (1): 9-17.

12. Murrieta JF, Juárez LA, Linares C, Zurita V. Prevalencia de gingivitis en un grupo de escolares y su relación con el grado de higiene oral y el nivel de conocimientos sobre salud bucal demostrado por sus madres. Bol Méd Hosp Infant Méx. Feb 2004; 61 (1): 44-54.

110

13. Secretaría de Salud y Seguridad Social de Pereira. Perfil epidemiológico de Pereira: Boletín epidemiológico de Pereira $\mathrm{N}^{\circ} 3$ [Internet]. [Consultado: 2013, 09, 01] Disponible en: http:// www.dlspereira.gov.co/intranet/intradocuments/ webExplorer/boletin-epidemiol-gico-depereira-2012

14. Ramírez NA, Díaz MP, Reyes P, Cueca O. Educación lúdica: una opción dentro de la educación ambiental en salud. Seguimiento de una experiencia rural colombiana sobre las geohelmintiasis. Rev.Fac. Med. Jun 2011; 19(1): 23-36.

15. Jiménez A. Lúdica y neuroaprendizaje Lúdica Colombia [Internet] Pereira. [Consultado: 2014, 11, 1] Disponible en: http://www.ludica.com.co/ ensayos.html

16. Hernández Y, Olivera ML. Enfermedad periodontal y propuesta de un método educativo sanitario en un grupo de escolares. Revista de Ciencias Médicas de La Habana. [Internet]. 2007; 13, (1): 30-38.

17. Universidad de Antioquia, Facultad De Ciencias Sociales y Humanas, Centro de Estudios de Opinión. (s.f.). Conceptos básicos de qué es un taller participativo, cómo organizarlo, dirigirlo y evaluarlo. Disponible en http://ceo.udea.edu.co

18. Monroy L, Rodríguez J. Lúdica: una alternativa para el aprendizaje significativo de la suma y la resta en los niños de primero de primaria en los Centros Educativos Huellitas del municipio de Florencia y palma arriba del municipio de La Montañita en el departamento del Caquetá [Trabajo de grado título de: Licenciado en Pedagogía Infantil] Florencia, Caquetá: Universidad de la Amazonía. Facultad de Ciencias de la Educación, Departamento de Educación a Distancia Programa Licenciatura en Pedagogía Infantil; 2011.

19. Farias D; Rojas F. Estrategias lúdicas para la enseñanza de la matemática en estudiantes que inician estudios superiores. Paradígma. [Internet] 2010; 31 (2): 53-64.

20. Echeverri JH, Gómez JG. Lo lúdico como componente de lo pedagógico, la cultura, el juego y la dimensión humana. [Internet]. [Consultado: 2015, 05, 06] Disponible en: http://blog.utp. edu.co/areaderecreacionpcdyr/files/2012/07/ LO-LUDICO-COMO-COMPONENTE-DE-LOPEDAGOGICO.pdf

21. Gaete RA. El juego de roles como estrategia de evaluación de aprendizajes universitarios. Rev. Educación y Educadores. [Internet] 2011; 14 (2): 289-307.

22. Cruz Roja. Salud y Educación para la salud [Internet]. [Consultado 2015, 05, 14]. Disponible en: http://www.cruzroja.es/crj/docs/salud/ manual/001.pdf 
23. Gavidia CV. La educación para la salud en los manuales escolares españoles. Rev. Esp. Salud Pública [Internet]. Abr 2003; 77(2): 275-285.

24. Fermán IA, Guzmán FJ, Gómez C, Ochoa D, Perales G. La investigación en Educación para la Salud. Retos y perspectivas. Rev Med UV [Internet]. 2008; 8(1): 45-55.

25. Hernández R, Fernández C, Baptista P. Metodología de la investigación. $5^{\text {a }}$ edición [Internet]. Bogotá, Colombia: McgrawHill; 2010. [Consultado: 2014, 07, 03]. Disponible en: http://www. academia.edu/6399195/Metodologia_de_la_ investigacion_5ta_Edicion_Sampieri

26. Instituto de la UNESCO (Organización de las Naciones Unidas para la Educación, la Ciencia y la Cultura) para la Educación. Educación para la salud [Internet]. [Consultado 2015, 05, 14]. Disponible en: http://www.unesco.org/education/ uie/confintea/pdf/6b_span.pdf

27. Cabrera CE, González G, Vega MG, Arias ED. Impacto de la educación participativa en el índice de masa corporal y glicemia en individuos obesos con diabetes tipo 2. Cad. Saúde Pública. [Internet]. 2004; 20(1):275-281.

28. Ministerio de Salud (Perú). Determinantes sociales de la Salud en Perú. Cuadernos de promoción de la salud $\mathrm{N}^{\circ}$ 17. [Internet] [Consultado: 2014, 10, 03] Disponible en: http://www.minsa.gob.pe/ dgsp/archivo/salud_mental_documentos/12_ Determinantes_Sociales_Salud.pdf

29. Ministro de Salud y Protección Social. Plan Decenal de Salud Pública 2012-2021 [Internet] [Consultado:
2014, 06, 29] Disponible en: http://www.minsalud. gov.co/Documentos \% 20y \% 20Publicaciones/ Plan \% 20Decenal \% 20-\% 20Documento \% 20en \% 20 consulta \% 20para \% 20aprobaci \% C3 \% B3n.pdf

30. Agudelo AA, Martínez E. La salud bucal colectiva y el contexto colombiano: un análisis crítico. Rev. Gerenc. Polit. Salud. [Internet]. 2009; 8 (16), 91-105.

31. Vesga C, Cáceres FM. Eficacia de la educación lúdica en la prevención del Dengue en escolares. Rev. Salud Pública. [Internet]. Ago. 2010; 12(4): 558569.

32. Arcega A, Celada NA. Control de pacientes con diabetes. Impacto de la educación participativa versus educación tradicionales. Rev Med Inst Mex Seguro Soc. 2008; 46 (6): 685-690.

33. Almeida TJ, Salvador PTCO, Alves KYA, Sousa ICA Playful education in health: report of an experience of "luminescent nurses". Rev. Pesqui. Cuid. Fundam. 2013; 5(5): 122-130.

34. Ausubel D. Teoría del aprendizaje significativo [Internet]. [Consultado: 2014, 11, 01] Disponible en: http://delegacion233.bligoo.com.mx/media/ users/20/1002571/files/240726/Aprendizaje_ significativo.pdf

35. Palazzo LS, Bérla JU, Tomasi E. Adolescentes que utilizan servicios de atención primaria: ¿Cómo viven? ¿Por qué buscan ayuda y cómo se expresan? Rev. Cad. Saúde Pública. Nov-Dic 2003; 19 (6): 1655-1665.

36. Kort F, Skinner. La terapia cognitiva. Revista Latinoamericana de Psicología. 1991; 23(2): 247-251.

37. Granda E. ¿A qué llamamos salud colectiva, hoy? Rev Cubana Salud Pública. 2004; 30(2): 1-20.

Para citar este artículo: Sánchez-Peña M, Sánchez-Delgado K, Agudelo-Ramírez A. Estrategias lúdicas para aumentar el conocimiento de un grupo de adolescentes escolarizados sobre la gingivitis. Duazary. 2015 dic; 12 (2): 100 - 111 